\title{
Reforma conventual: atuação feminina no México setecentista*
}

\author{
Luciana Gandelman**
}

Em meados do século XVIII a cidade do México, capital do vice-reino da Nova Espanha e sede do arcebispado, estava em plena expansão. Segundo os censos do período, a cidade contava com algo em torno de 112.462 habitantes, sendo possivelmente a maior da América. Por suas numerosas e movimentadas ruas espalhavam-se 84 igrejas, 7 hospitais, 9 colégios de meninos, 2 escolas de meninas, 1 academia de artes, 1 escola de mineração, 1 universidade, 36 mosteiros de religiosos, alguns recolhimentos de mulheres e 19 conventos femininos.

Os conventos de religiosas no México recebiam um público heterogêneo de mulheres, pertencentes a diferentes etnias $e$ estatutos sociais, divididas hierarquicamente em um complexo rol de postos e funções. Essas instituições, pilares fundamentais da sociedade mexicana, desempenhavam a um só tempo os papéis de instituições religiosas, casas de seguridade social e locais de apoio a estratégias familiares ligadas a herança, sucessão, casamento, prestígio e honra. Os conventos tiveram diferentes graus de crescimento e prosperidade, sendo que alguns chegaram a reunir uma considerável parcela da população feminina da elite, alcançando, por conseguinte, poderio político e econômico. $\mathrm{Na}$ segunda metade do século XVIII, essas instituições, graças à atuação de dois arcebispos, passaram por um conturbado

\footnotetext{
* Resenha do livro: ARENAS, Isabel. Dos arzobispos de Mexico - Lorenzana y Núnez de Haro - ante la reforma conventual femenina (1766-1775). León, Universidad de León, 2004. Recebida para publicação em abril de 2006.

** Pós-doutoranda na Cátedra Jaime Cortesão - USP. lucianagandelman@yahoo.com.br
} 
Atuação feminina no México setecentista

processo de reforma. As propostas de reforma desses prelados geraram fortes polêmicas que ultrapassaram os muros dos conventos e envolveram a sociedade mexicana como um todo, de autoridades eclesiásticas e civis a famílias da elite e homens da governança local. Foi com o objetivo de entender esses acontecimentos que a historiadora espanhola Isabel Arenas Frutos se debruçou sobre os governos eclesiásticos dos arcebispos Don Francisco Antonio Lorenzana e Don Alonso Núñez de Haro, no livro que é o tema desta resenha.

O livro de Isabel Arenas faz parte da coleção intitulada Tradición Clásica y Humanística en España e Iberoamerica, publicada pela Universidade de Léon, que procura entender o pensamento humanístico espanhol e seus desdobramentos nos períodos do barroco e da ilustração. A pesquisa da autora situa-se, portanto, no conjunto das investigações que procuram avaliar o impacto do pensamento ilustrado na Europa e na América e as mudanças ocasionadas pela ilustração nessas sociedades. Assim sendo, Arenas situa o recorte temporal de sua investigação na segunda metade do século XVIII, especialmente entre os anos de 1766 e 1775, período correspondente à atuação do mencionado arcebispo, Don Francisco Antonio Lorenzana e a parte do governo de seu sucessor, Don Alonso Núñez de Haro. Ambos os religiosos haviam nascido em famílias fidalgas da Espanha durante a década de 20 do século XVIII. Don Francisco Antonio Lorenzana iniciou seus estudos com os jesuítas e os beneditinos e, ainda na primeira metade do século XVIII, estudou Leis e Cânones em diversas universidades espanholas, construindo uma carreira eclesiástica na Espanha. Quando, em 1766, foi nomeado arcebispo do México e rumou para a América junto com o novo vice-rei, Marquês de Croix, trouxe consigo, segundo a autora, um espírito marcado por influências do pensamento ilustrado e regalista de então. De forma semelhante, seu sucessor a partir de 1772, Don Alonso Nùñez de Haro, educado pelo tio cônego e posteriormente pelos dominicanos $e$ formado em filosofia e teologia por universidades italianas, manteria essa tendência, ainda que com uma atuação 
menos incisiva. Ao longo de seus governos, os dois arcebispos tiveram de lidar com as pressões anticlericais presentes em certas facetas do pensamento ilustrado e regalista do período e com as conseqüentes demandas por reformas internas na Igreja $e$ nas ordens religiosas inspiradas por essa mesma corrente de pensamento. ${ }^{1}$

Entretanto, dentre todos os desafios apresentados por esse momento de inflexão na sociedade mexicana, Isabel Arenas interessa-se mais especificamente pelo impacto das reformas direcionadas aos conventos femininos existentes na cidade. Nesse sentido, o trabalho da autora insere-se não somente nos estudos acerca do impacto do pensamento ilustrado, mas também nas vertentes de investigação ligadas à história das mulheres, aos estudos da reclusão feminina e à história das instituições religiosas femininas. Desde pelo menos a década de 1980, os estudos sobre a reclusão feminina, tanto em instituições leigas quanto religiosas, vêm ganhando maior atenção de historiadores e pesquisadores como um aspecto importante para a compreensão das experiências femininas na Europa e em territórios ultramarinos ao longo da época moderna. A investigação sobre o fenômeno da reclusão feminina tem sido particularmente importante entre os historiadores ligados à história social e cultural da Europa católica e mediterrânea e suas colônias. ${ }^{2}$ No caso dos estudos sobre o

\footnotetext{
1 Entre as reformas, promovidas principalmente por Lorenzana, estavam a reorganização da divisão paroquial da cidade e das tarifas diocesanas, o estabelecimento de um plano de estudo para os seminários Espano-americanos, a reorganização das missões e da catequese dos índios enfraquecidas com a expulsão dos jesuítas e a reforma da disciplina interna nas ordens religiosas.

2 Sobre o caso brasileiro ver: AlgRANTI, Leila Mezan. Honradas e devotas: mulheres da colônia: condição feminina nos conventos e recolhimentos do sudeste do Brasil, 1750-1822. Rio de Janeiro, José Olympio, EdUnb, 1993; e Livros de devoção, atos de censura: ensaios de história do livro e da leitura na América portuguesa, 1750-1821. São Paulo, Hucitec, Fapesp, 2004; GANDELMAN, Luciana. Entre a cura das almas e o remédio das vidas: o recolhimento das órfãs da Santa Casa da Misericórdia do Rio de Janeiro e a caridade para com as mulheres, 1739-1830. Dissertação de mestrado, História,
} 
Atuação feminina no México setecentista

México, o trabalho de Isabel Arenas vem se reunir ao pioneiro livro de Josefine Muriel, intitulado Los recogimientos de mujeres. respuesta a una problemática social novohispana ${ }^{3}$, publicado em 1974, e a obras mais recentes, como a coletânea de artigos organizada por Asunción Lavrin e Rosalva Loreto López, intitulada Monjas y beatas. La escritura feminina em la espiritualidad barroca novohispana, siglos XVII y XVII ${ }^{\sharp}$, entre outros. $^{5}$

Acompanhando os desdobramentos da história das mulheres $e$ dos estudos das relações de gênero, as pesquisas acerca da reclusão feminina, ao darem visibilidade às experiências femininas, têm evitado a vitimização das mulheres e buscado entendê-las como agentes sociais imersos em redes de relação, poder, obrigação e solidariedade que ora possibilitam ora restringem seu campo de atuação. Arenas reconhece que as possibilidades de atuação feminina nas sociedades modernas ibero-americanas eram de certa forma limitadas pela organização

Unicamp, 2001; e Mulheres para um império: órfãs e caridade nos recolhimentos femininos da santa Casa da Misericórdia (Salvador, Rio de Janeiro e Porto século XVIII). Tese de doutorado, História, Unicamp, 2005; ALmEIDA, Suely Creusa Cordeiro de. O sexo devoto: normalização e resistência feminina no Império Português -XVI-XVIII. Tese de doutorado, História, Recife, CFCH/UFPE, 2003.

3 MURIEL, Josefina. Los recogimientos de mujeres: respuesta a una problemática social novohispana. México, Universidad Nacional Autónoma de México, Instituto de investigaciones históricas, 1974.

4 LAVRIN, Asunción e LÓPEZ, Rosalva Loreto. (eds.) Monjas y beatas. La escritura feminina en la espiritualidad barroca novohispana, siglos XVII y XVIII. México, Universidad de las Américas (Puebla)- Archivo General de la Nación, 2002.

${ }^{5}$ Ver ARENAS FRUTOS, Isabel. Fundación y primeros tiempos del convento de Jesús María de México (1580-1600). Actas del I Congreso Internacional de la Orden Concepcionista. Léon, Universidad de Léon, 1990, 2 vols; ver também: LÓPEZ, Rosalva Loreto. Los conventos femininos y el mundo urbano de la Puebla de los ángeles del siglo XVIII. México, El Colegio de México, 2000; e MEDINA, M. Ramos. (ed.) Memoria del II Congreso Internacional "El monacato feminino en el Imperio Español. Monasterios, beaterios, recogimientos y colegios". Homenaje a la Dra. Josefine Muriel. México, Condumex, 1995. 
patriarcal da sociedade, cujas instituições, legislação e agentes reforçavam constantemente a submissão feminina. Uma das grandes desvantagens enfrentadas pelas mulheres no período, aponta a autora, seria o fato de terem poucas oportunidades de se organizar e de atuar em grupo e, portanto, de carecerem de uma rede ampla de conexões que reforçasse seus esforços individuais $e$ canalizasse suas ações coletivas dentro da sociedade. Segundo Arenas, entretanto, os conventos representaram uma certa exceção a esse contexto, pois foram espaços onde as mulheres puderam formar seus próprios círculos de relações, seu próprio governo e sua própria prática administrativa, ainda que estivessem externamente sujeitas à hierarquia masculina da Igreja. Nesses casos, de acordo com Arenas, as mulheres experimentaram um notável grau de independência como grupo.

Foi buscando justamente esses espaços onde as mulheres possuíam maior possibilidade de atuação que Isabel Arenas voltou seu olhar para as instituições religiosas femininas $e$ mais especificamente para a proposta de reforma dessas instituições na segunda metade do século XVIII. A opção da autora por investigar um momento de inflexão e de reforma auxilia a concretização do objetivo de observar as possibilidades de atuação feminina na medida em que o período analisado é de embate. Como se trata de uma questão que mobilizou considerável parcela da sociedade da capital do vice-reinado da Nova Espanha, Arenas se preocupa em dar voz, na medida do possível, aos diversos grupos e agentes sociais envolvidos. Nesse sentido, as personagens de seu livro não são apenas os arcebispos e autoridades religiosas, mas também as religiosas e suas redes de relações, ainda que a atuação das autoridades seja o foco central e o componente de maior visibilidade na documentação e no trabalho da autora.

As fontes selecionadas e utilizadas pela autora, algumas delas reproduzidas em anexo documental, ajudam a reconstruir as etapas do embate e, dessa forma, a compor o painel dos vários aspectos e dos diferentes agentes envolvidos. O cerne de suas pesquisas está, portanto, baseado na documentação produzida 
Atuação feminina no México setecentista

pela polêmica em torno da reforma conventual. O material utilizado por Arenas inclui primeiramente documentos produzidos pelos arcebispos e demais autoridades religiosas - cartas, pastorais $e$ editos - elaborados no contexto do início do governo eclesiástico de Don Francisco Antônio Lorenzana e de suas primeiras tentativas de implantar a reforma da vida conventual. $\mathrm{O}$ desenrolar das polêmicas prosseguiu e se desenvolveu no interior dos debates do IV Concílio Provincial do México, possibilitando o alargamento da documentação para incluir as atas, os decretos, as representações $e$ as correspondências relativas ao mencionado concílio e demais cartas, editos e posturas subseqüentes. Isabel Arenas conseguiu reunir, ao longo de todo o período, documentação que nos oferece indícios da posição das religiosas sobre a questão e de suas tentativas de fazer valer sua voz nas disputas acerca da referida reforma. Arenas reuniu, ainda, documentação de autoridades civis e cartas régias que atestam a amplitude da polêmica gerada pelas reformas propostas pelos arcebispos e seu alcance na sociedade mexicana.

Diferentemente da política adotada pela coroa portuguesa para seus territórios americanos, a coroa espanhola aparentemente não impôs tantas barreiras à criação de instituições religiosas femininas em seus territórios americanos. ${ }^{6}$ Como resultado, a cidade do México contava no século XVIII com 19 conventos de religiosas, alguns deles presentes desde o século XVI, ao passo que Salvador, uma das principais cidades da América portuguesa no período, contava com apenas quatro. ${ }^{7}$ Os conventos mexicanos do período pré-reforma dividiam-se em dois tipos: o de "religiosas descalças" (descalzas ou rigoristas), que seguiam o modelo de "vida comum" e cumpriam o voto de pobreza, e o de "religiosas calçadas" (calzadas ou holgadas), que

${ }^{6}$ Sobre a política da Coroa portuguesa de restringir a criação de conventos e sua justificativa na preocupação com a promoção do casamento nos territórios ultramarinos ver: ALGRANTI, L.M. Honradas e devotas... Op. cit.

7 Para uma listagem dos conventos na América portuguesa do século XVIII, ver ID., I.B., pp.34-35. 
seguiam as regras próprias de cada ordem religiosa, porém mais amenas, e cultivavam a "vida particular", isto é, não eram obrigadas a partilhar refeitório e dormitório comuns, devendo partilhar apenas os atos religiosos. Além disso, este último tipo de convento admitia grandes contingentes de mulheres leigas $e$ meninas como educandas. ${ }^{8}$ Como mostra Isabel Arenas, os conventos de religiosas calçadas seriam justamente o alvo das propostas de reformas dos arcebispos, devendo passar da "vida particular", considerada pouco compatível com os preceitos da ortodoxia católica, à "vida comum". O interesse da autora se voltou especialmente para os conventos que estavam sob a jurisdição do ordinário, ou seja, dos arcebispos e que totalizavam 10 instituições. $^{9}$

Dentre essas instituições, quase todas fundadas ainda no século XVI ou nas primeiras décadas do século XVII, encontravamse alguns dos maiores e mais poderosos conventos da cidade do México, como era o caso dos conventos de La Concepción, de Jesús Maria e de San Jerónimo. Os conventos calçados da cidade, como afirma Isabel Arenas, contavam com uma numerosa população interna composta por um público variado de mulheres - das chamadas religiosas de hábito negro, ou seja, religiosas que já haviam professado, até noviças, serventes $e$ seculares, passando por meninas educandas e agregadas - todas organizadas hierarquicamente em seu interior. As religiosas possuíam "reservas" e "pecúlios", ou seja, recursos angariados de várias formas, os quais administravam por conta própria, o que

\footnotetext{
8 A divisão entre calçadas e descalças refere-se à reforma feita por santa Teresa de Ávila, na Espanha, ao fundar o convento carmelita de São José em 1562, cuja regra serviu de modelo a conventos posteriores chamados "descalços", os quais passaram a se organizar em pequenas comunidades, observando estrita pobreza, clausura e silêncio.

9 Conventos: La Concepción (1540), Nuestra Señora de La Natividad y Regina Coeli (1570), Nuestra Señora de Balvanera (1573), Jesús Maria (1580), San Jerónimo (1585), La Encarnación (1593), San Lorenzo (1599), Santa Inés (1599), San José de Gracia (1610) e San Bernardo (1636).
} 
Atuação feminina no México setecentista

acarretava grandes diferenças e desigualdades nas rendas de recolhidas que conviviam numa mesma instituição. ${ }^{10}$ Como conseqüencia disso, e da prática da "vida privada", as religiosas cuidavam, juntamente com suas criadas e agregadas, de suas vestimentas e adereços, tornando-os mais ou menos luxuosos, de acordo com suas possibilidades e inclinações. De forma análoga, as recolhidas faziam sua comida, com a ajuda de suas servas e em suas celas, e assim controlavam não só a sua própria alimentação como também a sociabilidade dos momentos de refeição.

Como argumenta Isabel Arenas, o espaço dos conventos, desenvolvido em conjunto com a consolidação da prática da "vida privada", criou uma arquitetura singular que as assemelhava a pequenas cidades, compostas por amplas celas, muitas vezes construídas e anexadas aos conventos pelas famílias das religiosas, as quais reproduziam os ambientes familiares dos grandes sobrados da elite mexicana. Nesse ambiente, convivia ao redor das religiosas um considerável número de mulheres organizadas em categorias mutáveis e altamente adaptáveis, que variavam entre educandas, agregadas, moças e serventes, acomodando um amplo leque de relações e redes de clientela e obrigação no seu interior. Nesses espaços compostos por tantos elementos privados $e$ habitados por um contingente amplo e diversificado de mulheres, os níveis de autonomia das religiosas e o seu contato com o exterior eram igualmente bastante flexíveis.

Foi contra esse universo, segundo Arenas, que o arcebispo ilustrado e regalista investiu quando chegou ao México e decidiu pela necessidade de reforma da vida religiosa na América espanhola. ${ }^{11}$ Essa polêmica não era nova, desde pelo menos o

\footnotetext{
${ }^{10}$ As rendas das religiosas advinham de diversas fontes, entre elas: renda de dinheiro posto a juros pelas suas famílias; somas fornecidas pelos próprios conventos; dinheiro adquirido com os chamados lavores femininos (costura $e$ culinária), esmolas, doações e presentes de fiéis.

${ }^{11}$ Segundo Isabel Arenas, o arcebispo Don Francisco Antonio Lorenzana não estava sozinho em sua iniciativa de reforma. Seu contemporâneo, Don Francisco
} 
Concílio de Trento medidas para reformar a vida religiosa, tornando-a mais próxima dos evangélios e das normas da Igreja, eram tentadas na Europa. Para a autora, entretanto, ao chegar ao México o arcebispo Lorenzana teria seu desejo de reforma alimentado pelos ventos anticlericais soprados pelo pensamento ilustrado. Como conseqüência, suas iniciativas, desde as pastorais até a atuação no Concílio do México, rumaram no sentido de abolir a vida particular $e$ instituir a vida comum $e$ o cumprimento do voto de pobreza, o que na prática significou algumas determinações: 1) proibia-se a negociação e a construção de celas para uso privativo e estabelecia-se o uso coletivo de todos os espaços dos conventos; 2) limitava-se o número de religiosas de hábito negro, branco e extranumerárias; 3) proibia-se a permanência de meninas, agregadas e seculares no claustro; 4) restringia-se o número de servas particulares por religiosa. Além disso, a obrigação ao voto de pobreza limitava igualmente os resursos de "pecúlios" e "reservas", assim como regulamentava a vestimenta, que deveria ser igual para todas e a refeição, que deveria ser feita coletivamente no refeitório.

A rejeição à reforma nos conventos foi grande. Como argumenta Arenas, as religiosas não aceitaram ou se resignaram facilmente e promoveram uma verdadeira guerra que opunha de um lado as hierarquias eclesiásticas e civis masculinas e de outro as próprias religiosas e seus aliados, familiares $e$ autoridades locais. A resistência dos conventos foi, de início, variada e isolada, mas ao longo do conflito, afirma a autora, os conventos foram alcançando um grau de articulação que jamais haviam experimentado antes. Ainda que tenham variado um pouco com o tempo $e$ entre as diversas instituições, os argumentos para a rejeição acabaram por formar um discurso de repúdio comum. De modo geral, as religiosas argumentavam que os conventos não tinham espaço ou recursos para promover as mudanças previstas

Fabian y Fuero, também implementou reforma semelhante quando foi bispo de Puebla de los Ángeles. 
Atuação feminina no México setecentista

pela reforma; que haviam professado nas antigas regras da "vida privada" e que não tinham saúde ou inclinação para a chamada "vida rigorista"; e que as condições de vida e a forma como haviam sido criadas nos territórios americanos faziam com que esse modo de vida proposto fosse excessivamente duro para sua constituição e costumes.

À medida que a reforma foi avançando, juntamente com a polêmica, as cisões apareceram não somente entre as religiosas e as autoridades, mas também dentro das instituições, dividindo as recolhidas entre adeptas e resistentes à proposta do arcebispo. A polêmica com as autoridades religiosas começaria a perder força com uma carta régia de 1774 que confirmou a reforma, mas ao mesmo tempo estabeleceu que as novas regras da "vida comum" seriam aplicadas apenas às religiosas que optassem por essa mudança ou às noviças que professassem dali por diante. Essa medida, entretanto, não amenizou as disputas internas nos conventos e a cisão entre adeptas e refratárias à reforma apenas se aprofundou. Seja como for, argumenta Isabel Arenas, as reclamações dos conventos cessaram a partir de 1775 e a resistência das religiosas à mudança, ainda que não tenha se apagado, passou a ser mais silenciosa e velada. Por fim, de acordo com Arenas, a reforma não teve na prática o sucesso esperado, pois o cotidiano dos conventos prosseguiu com certa autonomia. Essas instituições continuaram, por exemplo, a receber mulheres leigas de familias importantes, acompanhadas de um considerável número de criadas, e meninas continuaram a ser aceitas como educandas.

Em seu livro Isabel Arenas buscou analisar o impacto das propostas reformistas, de inspiração ilustrada e regalista, nos territórios ultramarinos na segunda metade do século XVIII. Mais especificamente, sua investigação nos oferece uma reflexão acerca dos efeitos dessa política sobre as instituições femininas de reclusão que então proliferavam na cidade do México. Essa escolha não poderia ser mais adequada, pois o espírito reformador que impulsionou o século XVIII e inspirou autoridades 
régias e civis a pressionarem a Igreja $e$ as ordens religiosas por uma revisão de seus privilégios, formas de atuação e organização interna, incidiu sobre as religiosas e sobre as mulheres em geral com empenho singular. Como argumentou Leila Mezan Algranti, a idade moderna assistiu à perda paulatina dos direitos das mulheres $e$ ao crescimento de um discurso controlador das condutas femininas e o século XVIII fecharia ainda mais o cerco em torno das mulheres, pressionando-as com as demandas em torno da honra sexual. ${ }^{12}$ Desta maneira, incidiram sobre as religiosas no período tanto as pressões reformadoras que pressionavam a Igreja como um todo quanto as demandas que se intensificavam sobre as mulheres. $O$ trabalho de Arenas demonstra vivamente essa convergência de demandas sobre os conventos femininos no período. Se analisarmos cuidadosamente o embate travado entre as autoridades $e$ as religiosas, podemos observar que a religiosidade feminina proposta pelos reformadores intentava, sob o pretexto de reforçar e recuperar os tradicionais ideais de clausura obediência recomendados pela doutrina da Igreja para a reclusão feminina, reduzir a autonomia $e$ a capacidade de atuação das religiosas. Tal intento enfrentou a resistência das religiosas que buscavam preservar e defender sua experiência de religiosidade e reclusão.

Além de aprofundar essa problemática do impacto das reformas de inspiração ilustrada e regalista sobre as vivências femininas, o trabalho de Isabel Arenas oferece oportunidades de reflexão para aqueles que se debruçam sobre a questão da reclusão feminina na época moderna. O caso da Nova Espanha difere bastante do da América portuguesa, pois além de não contar com tantas e tão variadas instituições religiosas para mulheres, esta última não passou por um processo de reforma tão sistematizado e incisivo quanto a primeira. Ainda assim, alguns pontos podem servir de inspiração para as pesquisas sobre a reclusão feminina na América portuguesa. Especialmente

\footnotetext{
${ }^{12}$ Sobre a questão ver: AlgRANTI, L.M. Honradas e devotas... Op. cit., p.321.
} 
Atuação feminina no México setecentista

importante no trabalho de Arenas foi a atenção dispensada pela autora à atuação das mulheres em meio à polêmica $e$ sua avaliação acerca dos diversos mecanismos utilizados pelas mesmas para defenderem, em última instância, seu modo de vida e sua autonomia. Nesse sentido, é importante ressaltar que se tratou não apenas de um conflito entre autoridades e religiosas, ou entre uma religiosidade tradicional e uma nova religiosidade ilustrada, mas também entre indivíduos que traziam a visão de mundo da ilustração ibérica e uma experiência européia e agentes que estavam imersos em uma sociedade "criola", para utilizar a terminologia de Arenas, que apresentava particularidades na maneira como se organizava e ressignificava os códigos civis e canônicos da sociedade castelhana. Em meio ao conflito de gêneros e de mundos, as religiosas conseguiram se organizar numa atuação coletiva articulada, poucas vezes experimentada pelas mulheres da época moderna, quer estivessem na Europa ou na América. Podemos dizer que a busca para dar visibilidade a momentos da história como esse em que as mulheres atuaram coletivamente, ainda permanece como uma das tarefas devidas pelos pesquisadores que se voltam para as vivências femininas, principalmente, embora não exclusivamente, aqueles que se debruçam sobre as sociedades da época moderna. 